\title{
Reconciling the Dynamics of Language with a Grammar Handbook. The ongoing Pedalion grammar project
}

\author{
Toon VAN HAL \& Yannick ANNÉ \\ (University of Leuven $)^{1}$
}

Benefitting from recent developments and insights in the fields of technology, linguistics, and language didactics alike, the Greek grammar Pedalion ( $\underline{\mathrm{http}}$ ://www.pedalion.org/ - Ancient Greek $\pi \eta \delta \dot{\alpha} \lambda$ ıov means 'rudder') seeks to offer a contemporary instrument that is tailored to mastering and understanding ancient languages.

\section{Background: the limits of conventional grammars in language teaching}

For centuries, grammars have been indispensable tools for learning foreign languages. Whereas in recent decades emphasis in living language learning has been on communication-based rather than on grammaroriented methods, grammars are still of prime importance in teaching and learning languages that are no longer spoken. This can be explained by the fact that the study of classical languages mainly focuses on learning how to decode and interpret texts: the active language skills complementing receptive skills in the study of modern languages are largely absent. ${ }^{2}$ Furthermore, grammar cannot only help language learners in acquiring a firm command of a foreign language, it is also seminal in enhancing the learners' understanding of general linguistics and language structures.

The online Pedalion grammar, being both a reading aid and a general reference work, aims to overcome some limits that are inherent to static grammars. First, printed grammars are always destined to a specific readership. Grammars tailored to the needs of high school students will turn out to be unsatisfactory for university students and researchers. On the other hand, a more extensive grammar-perfectly suited for researchers - would probably be too overwhelming for beginning students. Second, a printed grammar is, by its own nature, based on a single and static taxonomy. We argue that this lack of dynamicity does not do enough justice to the nature of language.

Following the general principles of Functional Linguistics, one could consider every language as a complex system consisting of formal features (e.g. cases, prepositional phrases, word order, verbal moods, etc.), expressing a wide range of semantic notions (e.g. 'cause', 'future', 'exclamation') and fulfilling diverse functions, both syntactic (a basic distinction in this regard is the division between omissible and nonomissible constituents) and pragmatic (e.g. topic vs. focus, illocutionary forces etc.). ${ }^{3}$ In most languages, the interplay between formal, semantic, syntactic, and pragmatic features tends to be highly complex. This means that the interaction between these factors can normally only be conveyed as a many-to-many

\footnotetext{
${ }^{1}$ An earlier draft of this paper was presented at the Digital Classicist Berlin lecture series on 11 November 2014. We are very much indebted to the suggestions expressed by the participants. We would also like to thank the helpful remarks by two anonymous reviewers.

${ }^{2}$ Nevertheless, learning methods are available that do make use of immersion-based principles. For Latin, one can cite Ørberg $\left(1981^{1}\right)$, and for Ancient Greek, Saffire and Freis $\left(1999^{3}\right)$ and Rico (2009). Handbooks such as the Italian version of Athenaze (Balme et al., 2009) still make abundant use of the learner's language.

${ }^{3}$ The functional approach to linguistics, as outlined in reference works such as Dik (1997), has been successfully applied to Greek syntax by various authors, e.g. Emilio Crespo and Albert Rijksbaron (see also De la Villa, 2013).
} 
Precisely the grammar's dynamic character will stimulate the students to deal with Ancient Greek in a more flexible way. When making use of Pedalion, students will be trained

(a) to switch from the language's formal level to its semantic, syntactic, or pragmatic level and vice versa;

(b) to study the language from both a synchronic and a diachronic perspective;

(c) to appreciate the language-specific features of Greek in that the grammar also incorporates insights from general and typological linguistics.

The development of an online dynamic reading and learning grammar will allow our students to follow a learning path tailored to their individual levels and needs. Both the grammar's flexible taxonomical possibilities and the incorporation of the most recent linguistic and didactic insights will foster considerably the students' linguistic competences as they will acquire a more profound knowledge of the Ancient Greek language as well as of the Ancient Greek texts.

Relying on recent monographs, authoritative reference works and specialist articles in the fields of synchronic, diachronic, and typological linguistics in general and Ancient Greek linguistics in particular, ${ }^{6}$ the grammar will encompass recent insights into linguistics, thus guaranteeing its continued usefulness to students interested in conducting research in the growing field of historical linguistics. In addition, its authors are making intensive use of several linguistic corpora, including Alpheios, Perseus under PhiloLogic, Logeion, TLG and Iliados, thus allowing us to find new example sentences and to gauge the frequency of specific constructions, forms or collocations.

\footnotetext{
${ }^{6}$ The most important general reference grammars include Crespo et al. (2003) and Bornemann \& Risch (1978). As to the specialized books, one could mention Duhoux (2000) and Rijksbaron (1994) for the verbal system, and Luraghi (2003) and Bortone (2010) for the syntax of prepositions and cases. Despite being outdated from a linguistic point of view, traditional school grammars such as Smyth (first edition 1916) and Goodwin (189o) remain invaluable sources of author-specific remarks and examples. The new three-volume Encyclopedia of Ancient Greek Language and Linguistics (Giannakis 2014), which encompasses a wide array of articles discussing Greek linguistics from divergent perspectives and approaches, is a recent goldmine of information.
} 


\subsection{Micro-structure: The structure of a paragraph}

The grammar's flexibility resides in the specific design of its elementary brick-stones ('paragraphs'). This is, in a simplified way, how a prototypical paragraph looks like (Figure 1):

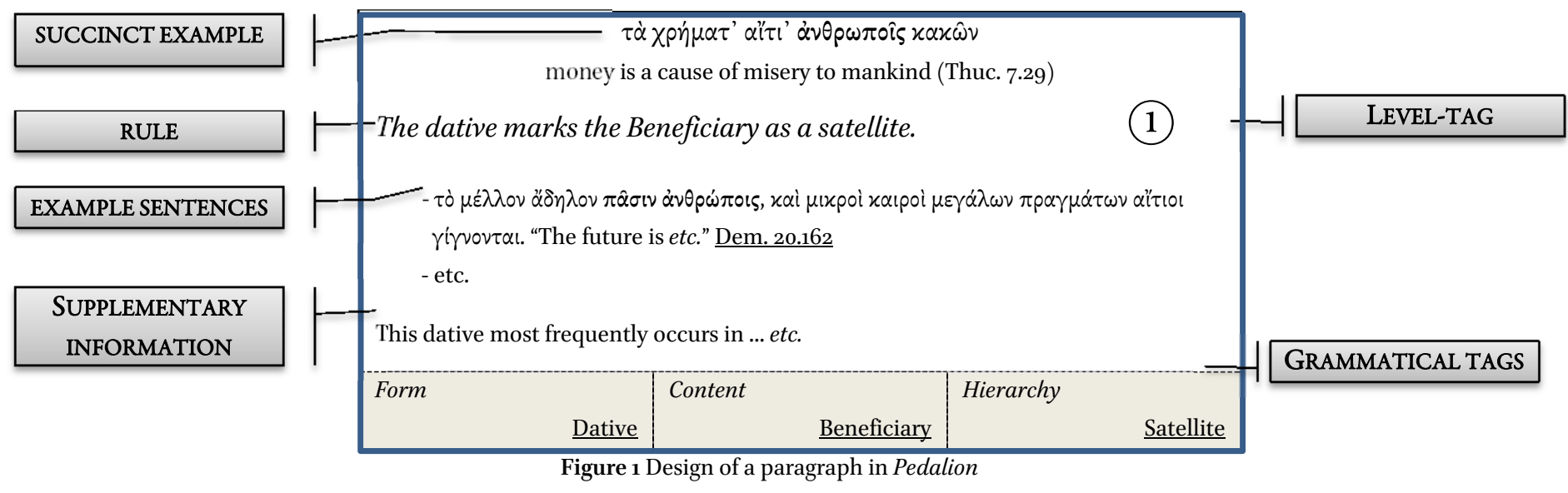

- The SUCCINCT EXAMPLE serves as a first introduction to (and illustration of) the grammatical rule to be dealt with. Being as short as possible, it can also be regarded as a mnemonic operator.

- The grammatical RULE, phrased in a systematic and formulary way, offers formal, semantic, and syntactic information.

- Partly determined by corpus-based parameters, the LEVEL TAG specifies the rank and significance of the rule (fundamental: (1), basic: (2), advanced: (3), specialized: (4)).

- In sharp contrast to most extant grammars of Ancient Greek, Pedalion seeks to adopt a high rate of original EXAMPLE SENTENCES extracted from classical works (with special attention for authors being central in the Leuven curriculum of Ancient Greek studies). A link to the Perseus Library ensures that the users can study these sentences in their original textual context.

- The SUPPLEMENTARY INFORMATION offers more details on lexical patterns and syntactical behaviour related to the rule, as well as on its frequency and its historical background.

- The clickable GrammatiCAL TAGS, divided into three categories (FORM, CONTENT, and HIERARCHY - see 2.1) provide the users with some general and cross-linguistic background. More importantly, these tags also lie at the basis of the grammar's ultimately flexible backbone. A more complex rule states that 'ou $\mu \eta \dot{\eta}+$ indicative future denotes a strong negation'. For this rule, the grammatical tags are the following (Table 2):

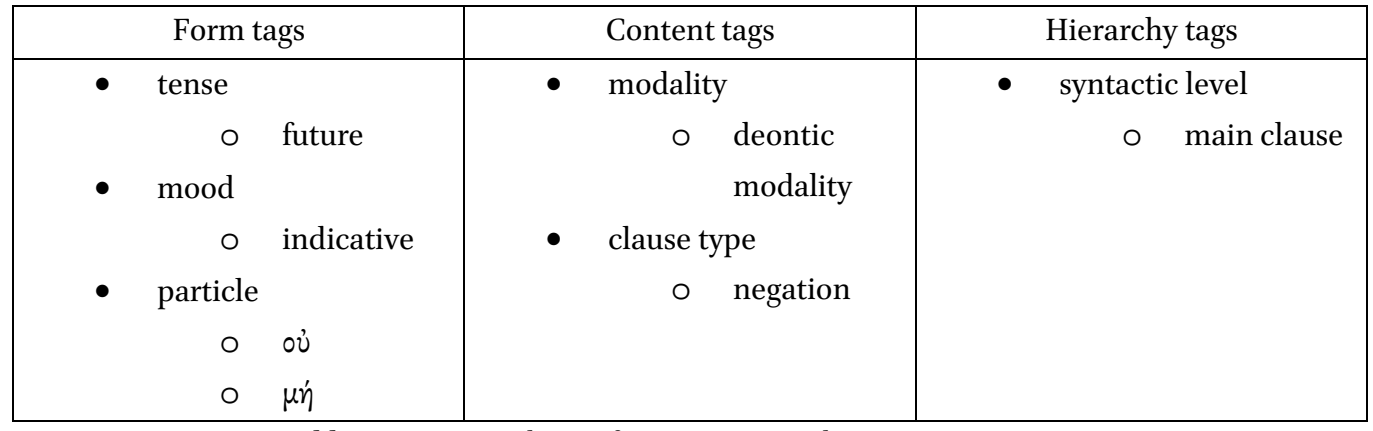

Table 2 Grammatical tags of a given paragraph

\subsection{Macro-structure: steering through the paragraphs}

Both the grammatical and the level tags have been implemented in a faceted search-environment, which allows the users to select multiple parameters in order to narrow down the full list of rules. In doing so, they 
can find in an efficient manner the data they desire. So, for instance, a student reading a Greek text will be able to select 'Dative' (formal tag) and 'Satellite' (syntactic tag) so as to generate a survey of the many semantic roles the dative case can denote (e.g. Manner, Instrument, Cause, etc.). By selecting the tag 'Purpose', on the other hand, a student making a translation from Dutch into Ancient Greek, will discover the range of formal means with which this semantic notion is expressed: cases, prepositions, subordinate clauses, infinitives and participles, etc.

\section{$\pi \eta \delta \dot{\alpha} \|_{10}$}

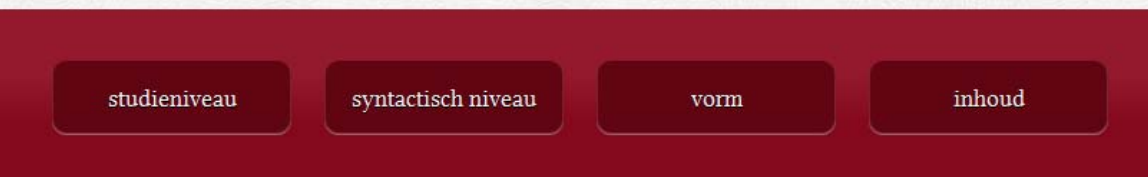

Figure 1 Pedalion's four types of filters: study level (studieniveau), syntactical level (syntactisch niveau), form (vorm), and content (inhoud).

Hence, one and the same set of paragraphs will serve as brick-stones to build 'different' grammars. As a consequence, Pedalion will serve not only as a reference grammar, but also as a reading grammar and as a learning grammar. Table 2 gives an illustrative overview of the content tags related to verbal categories.

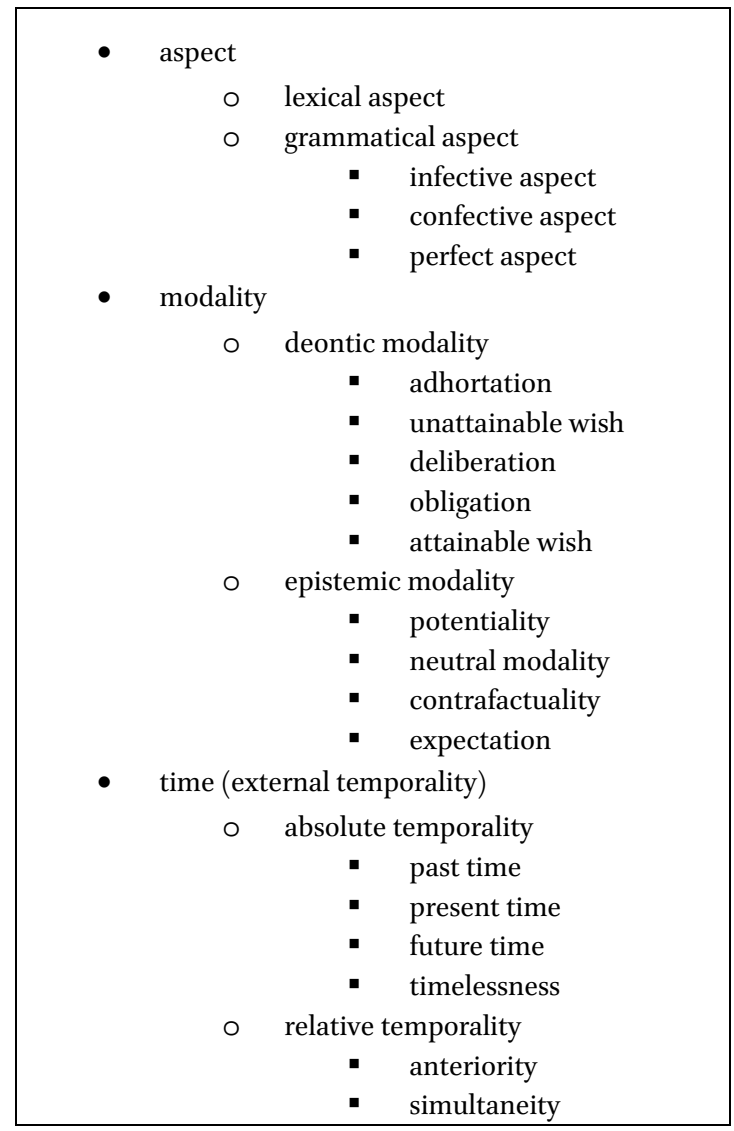




\subsection{Technological details}

The Pedalion grammar has been designed in a relational Filemaker database, all tables of which can be easily exported to other formats such as csv, thus ensuring its future sustainability. ${ }^{7}$ Importantly, the database structure is based on persistent stable identifiers, i.e. unique numbers assigned to each grammatical rule. These identifiers are not linked to any specific hierarchy, as are the paragraph numbers in a traditional grammar book. This allows for stable URLs, even when changing insights would change a rule's title or classification. Furthermore, the stable identifiers allow for links between different applications (i.e. between the grammar's examples and their source texts or between an exercise module and the relevant passage in the grammar) or between different language versions of the same grammar. ${ }^{8}$

The online application will run under Drupal, whose chief advantages for our purposes are its open-source character and its adaptability. The core functionality of this content manager is accompanied by an extensive range of modules being continuously developed and maintained by an active user community. The entire application will be freely accessible under a Creative Commons license. Essentially, a custommade faceted search module has been added to the basic Drupal system, ensuring ease of access for all users.

\section{Implementation in classroom learning}

Following the principles of blended or hybrid learning, Pedalion will be both a guide for classroom study and an online tool enabling students to explore the grammatical system of Ancient Greek at their own pace. During classes, a printed version-necessarily involving a static hierarchy_-will be used for teaching, although the electronic version will be frequently used for the sake of clarification, illustration, and comparison. Students will be stimulated to go beyond the printed grammar and explore the dynamics of grammar by using the online tool in their individual reading. Thanks to an adaptive interface, users will be able to consult Pedalion on any device, be it a personal computer, tablet, or smartphone. After encountering a GOAL expression in a Greek text under study, a teacher could, for instance, ask the students to come up with alternative constructions the Greek author could have used. The Pedalion grammar thus allows the students to explore Greek grammar in a creative and efficient way.

In addition, the project also encompasses an integrated exercise and assessment package, running under the Edumatic software. This software package is integrated in the Blackboard learning environment and actively used within the University of Leuven for learning modern languages. As such, it allows for the creation of various types of exercises (e.g. multiple choice, drop-down, fill in the gap, etc.). The feedback field will contain a link to the relevant Pedalion paragraph. Recent studies have confirmed the importance of instant feedback, which has been proven to contribute considerably to students' learning progress

\footnotetext{
${ }^{7}$ Tables have been created for the syntactic paragraphs, the examples (to be used both for the grammar and the exercises), the grammatical tags, and a number of other content types (e.g. morphological and phonological rules). All of these tables are interlinked in multiple ways.

${ }^{8}$ The importance of both advantages of persistent identifiers - i.e. their stability and their connectivity - has been highlighted in many other recent and ongoing projects, such as the Trismegistos Interdisciplinary Platform for Ancient World Texts and Related Information (see Depauw and Gheldof 2014).
} 
(López-Pastor 2013, with further references). During classes, there will be time to deal more extensively with questions and problems that have emerged when making the digital exercises at home.

\section{Future perspectives}

With the support of additional funding, the structures developed for Pedalion could be easily adapted for making a similar grammar for Latin. Greek has been prioritized, since no complete, up-to-date grammar of Ancient Greek exists in the Dutch language. ${ }^{9}$ Looking beyond the Dutch-speaking world, we are considering the possibility of making an English or French translation of the grammar, which in a best-case scenario could be interlinked with ongoing initiatives in the field of Digital Classical Humanities such as Perseus. The use of persistent stable identifiers in general opens many other perspectives. It will allow us to connect the contents of other e-learning applications (e.g. exercise modules) with the relevant rules in the grammar. We will also investigate to what extent the grammatical rules can be utilized in the framework of ongoing treebank projects of Ancient Greek texts. ${ }^{10}$

\section{References}

Balme, M., Lawall, G., Miraglia, L. and Bórri, T.F. (2009), Athenaze: introduzione al greco antico, Edizioni Accademia Vivarium Novum, Montella (Avellino).

Bornemann, E. and Risch, E. (1978), Griechische Grammatik, Moritz Diesterweg, Frankfurt am Main, 2nd ed.

Buchanan, T. (2001), "The efficacy of a World-Wide Web mediated formative assessment: WWW-mediated formative assessment", Journal of Computer Assisted Learning 16(3): 193-200.

Crespo, E., Conti, L. and Maquieira, H. (2003), Sintaxis del griego clásico, Gredos, Madrid.

Depauw, Mark, and T. Gheldof. (2014), "Trismegistos. An Interdisciplinary Platform for Ancient World Texts and Related Information," Theory and Practice of Digital Libraries - TPDL 2013 Selected Workshops, ( Bolikowski, Ł., Ed.), Springer, Cham, 40-52.

Desmet, P., Melis, L., Vleminckx, G., Sturbeaux, Y., Jacobs, P. and Speelman, D. (2001), "Un environnement puissant pour l'apprentissage de la grammaire du FLE: le projet ALFAGRAM", Actes des Colloques Usages des nouvelles technologies et enseignement des langues étrangères UNTELE (Kazeroni, A., Ed.), UNTELE, Compiègne, Vol. 1, 87-100.

Dik, S.C. (1997), The Theory of Functional Grammar. Part 1: The Structure of the Clause (Hengeveld, K., Ed.), Mouton de Gruyter, Berlin.

Duhoux, Y. (1992), Le verbe grec ancien: éléments de morphologie et de syntaxe historiques, Peeters, LouvainLa-Neuve.

Giannakis, G.K. (2013), Encyclopedia of Ancient Greek Language and Linguistics, Brill, Leiden, available at: http://referenceworks.brillonline.com/entries/encyclopedia-of-ancient-greek-language-andlinguistics/.

Goodwin, W.W. (1890), Syntax of the Moods and Tenses of the Greek verb, Ginn \& Co., Boston.

\footnotetext{
${ }^{9}$ Apart from school grammars with their necessary limitations, no complete grammars are available. Rijksbaron (200o) is a collection of capita selecta rather than a full-blown syntax. Van de Vorst (1954), despite being basically a school grammar from the 1930s, is so far the only useful alternative. For a complete grammar of Latin in the framework of Functional Linguistics, one could refer to Pinkster (1984).

${ }^{10}$ We are currently in touch with Giuseppe Celano (University of Leipzig), one of the driving forces of the Arethusa treebanking application (www.perseids.org/tools/arethusa/app/). In the near future, advanced students of the University of Leuven will be invited to treebank examples sentences of the new grammar by making use of the Arethusa system.
} 
López-Pastor, V. M. et al. (2013), "Formative assessment strategies and their effect on student performance and on student and tutor workload: the results of research projects undertaken in preparation for greater convergence of universities in Spain within the European Higher Education Area (EHEA)," Journal of Further and Higher Education 37(2): 163-180.

Ørberg, H.H. (1981), Lingua Latina per se illustrata, Museum Tusculanum, Hauniae.

Pinkster, H. (1984), Latijnse syntaxis en semantiek, Grüner, Amsterdam.

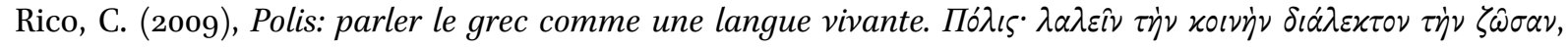
Éditions du Cerf, Paris.

Rijksbaron, A. (1994), The Syntax and Semantics of the Verb in Classical Greek: an introduction, Gieben, Amsterdam.

Rijksbaron, A., Slings, S.R., Stork, P. and Wakker, G.C. (2000), Beknopte syntaxis van het klassiek Grieks, Hermaion, Lunteren.

Saffire, P. and Freis, C. (1999), Ancient Greek Alive, The University of North Carolina Press, Chapel Hill, NC, 3rd revised edition.

Smyth, H.W. (1956), Greek Grammar, Harvard University Press, Cambridge.

De la Villa, J. (2013), "Functional Grammar and Greek", Encyclopedia of Ancient Greek Language and Linguistics (Giannakis, G.K., Ed.), Brill, Leiden, available at: http://referenceworks.brillonline.com/entries/encyclopedia-of-ancient-greek-language-andlinguistics/functional-grammar-and-greek-EAGLLCOM_0oooo138 (accessed 5 December 2014).

Van de Vorst S.I., K. (1985), Beginselen der Griekse spraakkunst. Bewerkt door A. Geerebaert S.I., H. Dessain, Luik (13th ed.). 